\title{
mathematical Modeling of a Moving Planar Payload PENDULUM ON FLEXIBLE PORTAL FRAMEWORK
}

\section{Pemodelan Matematik dari Pendulum Payload Bidang yang BergeraK di Atas Frame Portal FleKsibel}

\author{
Edwar Yazid \\ Research Centre for Electrical Power and Mechatronics - Indonesian Institutes of Sciences \\ Komp. LIPI Bandung, Jl Sangkuriang, Gd 20, Lt 2, Bandung, \\ West Java 40135, Indonesia \\ edwar.putra@gmail.com
}

Received: October $17^{\text {th }}, 2011$; Revised: November $1^{\text {st }}, 2011$; Accepted: December $9^{\text {th }}, 2011$; Published online: December $22^{\text {th }}, 2011$.

\begin{abstract}
Abstrak
Pemodelan matematik sebuah pendulum beban bidang yang bergerak di atas frame portal fleksibel ditampilkan dalam tulisan ini. Persamaan gerak dari sistem yang demikian diperoleh melalui pemodelan frame portal menggunakan elemen hingga bersamaan dengan metode elemen hingga bergerak dan pendulum beban bidang menggunakan persamaan Lagrange. Persamaan yang diturunkan menunjukkan adanya kaitan tidak linear antara dinamika portal frame dan pendulum beban. Teknik integrasi numerik gabungan langsung, yaitu Newmark- dan Runge-Kutta orde ke-empat selanjutnya digunakan untuk menyelesaikan persamaan gerak yang terkait tersebut. Beberapa simulasi numerik dilakukan dan hasilnya diverifikasi dengan beberapa perbandingan. Hasilnya menunjukkan bahwa amplitudo dan frekuensi dari sudut ayunan pendulum beban sangat dipengaruhi oleh fleksibilitas struktur dan kabel dalam hal kecepatan pembawa beban.
\end{abstract}

Kata kunci: Pendulum beban, portal framework, metoda elemen hingga bergerak, persamaan Lagrange.

\begin{abstract}
Mathematical modeling of a moving planar payload pendulum on elastic portal framework is presented in this paper. The equations of motion of such a system are obtained by modeling the portal frame using finite element in conjunction with moving finite element method and moving planar payload pendulum by using Lagrange's equations. The generated equations indicate the presence of nonlinear coupling between dynamics of portal framework and the payload pendulum. The combinational direct numerical integration technique, namely Newmarkand fourth-order Runge-Kutta method, is then proposed to solve the coupled equations of motion. Several numerical simulations are performed and the results are verified with several benchmarks. The results indicate that the amplitude and frequency of the payload pendulum swing angle are greatly affected by flexibility of structure and the cable in term of carriage speed.
\end{abstract}

Keywords: Payload Pendulum, Portal Framework, Moving Finite element method, Lagrange’s Equations.

\section{INTRODUCTION}

The vibrational motion induced by a suspended load moving on flexible structures is one of important vibration problems in variety of engineering systems, such as civil, aerospace and mechanical engineering. Generally, such a system may be found in crane systems which are most widely used in factories, warehouses, shipping yards and nuclear facilities. The constructions of crane's supporting structure are usually designed to have very strong structures and big dimension in order to lift and transfer suspended heavy loads. However, as the lifting capacities become higher, the size of crane increases significantly. This condition leads to the consequence that the elastic deformability of all elements of the structure cannot be neglected [1]. Furthermore, the presence of structural and cable elasticity is known to exhibit an inherent property of vibration when subjected to dynamic loads, leading to crane component or structural damage. If the crane system (trolley, hoist mechanism, rigging and payload) is taken as a moving subsystem, then this moving subsystem will induce the crane framework and conversely. They will create bidirectional dynamic interaction and constitute nonlinear coupling between crane and its framework, affecting the motion of each direction to each other.

However, to the best of author's knowledge, the published papers and conferences relate with 
this case are limited. Some cited references related to this paper can be referred in [2]-[7]. Among those references, paper [6] has studied such a case by introducing the concept of moving finite element method, but the dynamics of payload is not introduced in his work and restricted to rigid cable. He also discussed only dynamic responses of crane framework.

This paper is addressed to generate mathematical model of a moving planar payload pendulum by introducing the flexibility of portal framework and cable into the model in an effort to propose a computational technique for dynamic response prediction by which allow us to investigate the bidirectional dynamic interaction between the payload pendulum and portal framework. Moreover, the proposed mathematical model can be used for advance dynamic analysis and basis for controller design.

\section{Mathematical Modeling of SYSTEM}

\section{A. System Description}

A moving planar payload pendulum on flexible portal framework is manifestation of a planar gantry crane. This crane system can be divided into two subsystems, namely gantry crane and stationary crane framework. Gantry crane incorporates interaction among trolley, wire rope as hoist cable and payload which is manipulated by trolley and hoist mechanism. The payload is grabbed using hook system, which is then hoisted from trolley by means of cable. For convenience hereafter, trolley is called as carriage, payload as payload pendulum and crane framework as a portal frame.

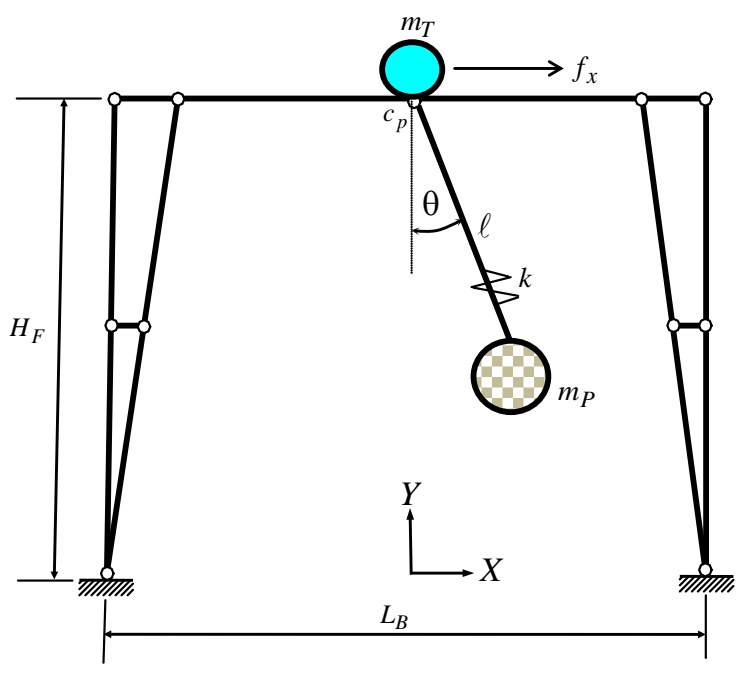

(a)
For simplicity of the characteristics of the physical gantry crane, several assumptions are put forward to the proposed mathematical model. Mass of carriage and payload pendulum is modeled as lumped mass which is connected by extensible hoist cable. Payload and its cable behave as pendulum model as depicted in Fig. 1. Because of its natural characteristic, the angle of the payload swing has one angle with respect to the inference frame. $\theta$ is denoted as angle between the $x_{T}$-axis and $x_{T} y_{T}$ plane as defined by Fig. 1b. The payload swings either small or large swing angles. Friction between carriage and the top beam of portal framework, hoist cable and drum in hoist system and dynamics of carriage and hoist drive mechanism are not considered.

The vibration effect of the entire motion portal framework can be negligible because of low and constant speed [8]. This assumption makes its supports can be fixed to the ground. Structural members of crane framework have constant cross-sections, materially and geometrically linear so it is only applicable for small deformation. Because the portal framework is classified as a planar frame, the used structural element is $2 \mathrm{D}$ beam element.

\section{B. System Modeling}

The equations of motion of the system can be derived by means of second order of Lagrange's equations, showing in eq (1).

$$
\begin{aligned}
& \frac{d}{d t}\left(\frac{\partial L}{\partial \dot{q}}\right)-\frac{\partial L}{\partial q}+\frac{\partial F_{R}}{\partial \dot{q}}=f_{i}, \\
& q=\left(u_{T}, v_{T}, x_{T}, \theta, \delta\right), \dot{q}=\left(\dot{u}_{T}, \dot{v}_{T}, \dot{x}_{T}, \dot{\theta}, \dot{\delta}\right) .
\end{aligned}
$$

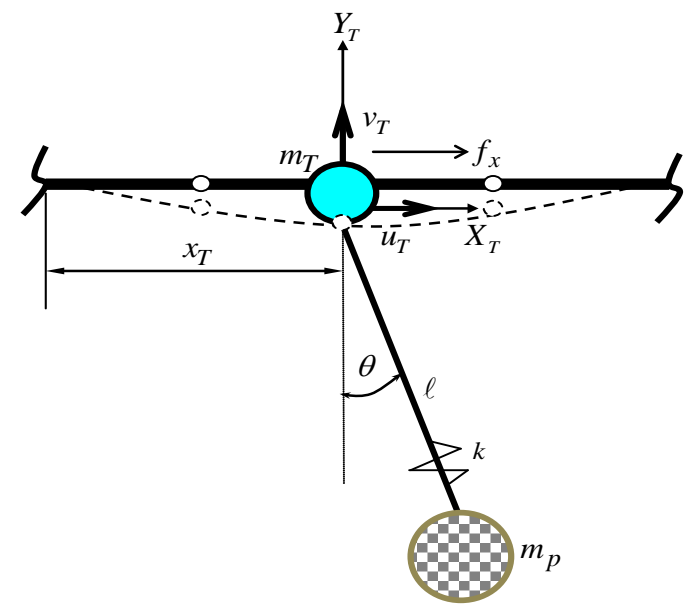

(b)

Figure 1. Overall system, (a) Finite element model of system, (b) Planar payload pendulum model on flexible portal framework. 
The first two terms of $q=\left(u_{T}, v_{T}, x_{T}, \theta, \delta\right)$ are defined as the generalized coordinates to describe the elastic deformation of portal framework in the two directions and the rest is payload pendulum motion.

General velocity of the system is $\dot{q}=\left(\dot{u}_{T}, \dot{v}_{T}, \dot{x}_{T}, \dot{\theta}, \dot{\delta}\right)$. The position vector of carriage $v_{T}$ and payload pendulum $r_{p}$ as shown in Fig. 1 can be expressed as

$$
\begin{aligned}
r_{T}= & \left(x_{T}(t)+u\left(x_{T}, t\right)\right) \cdot i+\left(H_{F}+v\left(x_{T}, t\right)\right) j \\
r_{P}= & \left(x_{T}(t)+u\left(x_{T}, t\right)+\left(\ell_{P}+\delta\right) \sin \theta\right) i \\
& +\left(H_{F}+v\left(x_{T}, t\right)-\left(\ell_{P}+\delta\right) \cos \theta\right) j
\end{aligned}
$$

Where $i, j$, and $k$ are unit vectors along the $\mathrm{x}-, \mathrm{y}-$, and z-axis, respectively. For convenience, elastic displacements in Eq. (2a)-(2b) can be expressed in terms below.

$$
\begin{aligned}
& u_{T}=u\left(x_{T}, t\right)=\left.u(x, t)\right|_{x=x_{T}}, \\
& v_{T}=v\left(x_{T}, t\right)=\left.v(x, t)\right|_{x=x_{T}} .
\end{aligned}
$$

The term $x_{T}$ is position of moving carriage along the span of top beam of portal framework $L_{B}$, which is time-dependent and so are terms $u_{T}, v_{T}$. It is seen also that the height of portal framework $H_{F}$ is included either in carriage or payload pendulum position with respective to the global coordinate system of portal framework. Referring to Eq. (2), the flexibility of portal framework $u_{T}$, $v_{T}$ and hoist cable $(\delta)$ is considered in the position vector of carriage and payload pendulum. The flexibility of hoist cable is modeled as one linear spring with stretched length $\ell$. This is sufficient approach since the cable is assumed to be in tension during normal crane operation [9]. The linear spring force of hoist cable is as follows.

$$
F_{k}=k \delta=k\left(\ell-\ell_{p}\right)
$$

It is noted that notation $k$ is cable stiffness, while $\ell_{P}$ is unstreched hoist cable. Generalized force is denoted as $f_{i}$, namely $f_{x}$ and $f_{y}$ which are applied input force for the $x$ and $y$ motions, respectively. Kinetics energy of the system $K$ is the kinetics energy of carriage and payload pendulum $K_{G}$ and portal framework $K_{F}$, defined as follows,

$$
K_{G}=K_{T}+K_{P}=1 / 2 m_{T} \cdot \dot{r}_{T}^{2}+1 / 2 m_{p} \cdot \dot{r}_{p}^{2}
$$

$$
\begin{aligned}
K_{F}= & \frac{1}{2}\{\dot{U}\}^{T}[M]\{\dot{U}\} . \\
& =\frac{1}{2}\left\{\begin{array}{l}
\dot{U}_{r} \\
\dot{u}_{T} \\
\dot{v}_{T}
\end{array}\right\}^{T}\left[\begin{array}{lll}
M_{r r} & M_{r u_{T}} & M_{r v_{T}} \\
M_{u_{T} r} & M_{u_{T} u_{T}} & M_{u_{T} v_{T}} \\
M_{v_{T} r} & M_{v_{T} u_{T}} & M_{v_{T} v_{T}}
\end{array}\right]\left\{\begin{array}{l}
\dot{U}_{r} \\
\dot{u}_{T} \\
\dot{v}_{T}
\end{array}\right\} .
\end{aligned}
$$

The total potential energy of the system $P$ is the potential energy of gantry carriage and payload pendulum $P_{G}$ and portal framework $P_{F}$, expressed as follows,

$$
\begin{aligned}
P_{G}= & P_{T}+P_{P}+P_{K} \\
= & \left(m_{T}+m_{p}\right) g H_{F}+\left(m_{T}+m_{p}\right) g v_{T} \\
& -m_{p} g\left(\ell_{P}+\delta\right) \cos \theta+1 / 2 k \delta^{2} \\
P_{F}= & \frac{1}{2}\{U\}^{T}[K]\{U\} \\
= & \frac{1}{2}\left\{\begin{array}{l}
U_{r} \\
u_{T} \\
v_{T}
\end{array}\right\}^{T}\left[\begin{array}{lll}
K_{r r} & K_{r u_{T}} & K_{r v_{T}} \\
K_{u_{T} r} & K_{u_{T} u_{T}} & K_{u_{T_{V}}} \\
K_{v_{T} r} & K_{v_{T} u_{T}} & K_{v_{T} v_{T}}
\end{array}\right]\left\{\begin{array}{l}
U_{r} \\
u_{T} \\
v_{T}
\end{array}\right\}
\end{aligned}
$$

Where $[M]$ and $[K]$ are global mass and stiffness matrices of the portal framework, $m_{T}$ and $m_{P}$ are carriage and payload mass, $\dot{r}_{T}$ and $\dot{r}_{P}$ are velocity vector carriage and payload pendulum, which can be obtained the time derivative of $r_{T}$ and $r_{P}$. Notation $U_{r}$ and its derivative indicate vectors of displacements and velocities for the rest of the degrees of freedom of the portal framework, while notations $\left(u_{T}, v_{T}\right)$ and its derivative indicate the nodal displacements and velocities with respect to the position vector of carriage and payload pendulum.

Notation $F_{R}$ in Eq. (1) is dissipation function which can be expressed,

$$
\begin{aligned}
F_{R} & =\frac{1}{2}\{\dot{U}\}^{T}[C]\{\dot{U}\} \\
& =\frac{1}{2}\left\{\begin{array}{l}
\dot{U}_{r} \\
\dot{u}_{T} \\
\dot{v}_{T}
\end{array}\right\}^{T}\left[\begin{array}{ccc}
C_{r r} & C_{r u_{T}} & C_{r v_{T}} \\
C_{u_{T} r} & C_{u_{T} u_{T}} & C_{u_{T} v_{T}} \\
C_{v_{T} r} & C_{v_{T} u_{T}} & C_{v_{T} v_{T}}
\end{array}\right]\left\{\begin{array}{c}
\dot{U}_{r} \\
\dot{u}_{T} \\
\dot{v}_{T}
\end{array}\right\} .
\end{aligned}
$$

In this paper, structural damping matrix $[C]$ in Eq. (7) is determined by means of Rayleigh damping theory.

The Lagrangian $L$ is defined as $L=K-P$ where $K$ is kinetics energy and $P$ is potential energy of the system and expressed in Eq. (8). 


$$
\begin{aligned}
L= & K-P, \\
L= & \frac{1}{2}\left\{\begin{array}{l}
\dot{U}_{r} \\
\dot{u}_{T} \\
\dot{v}_{T}
\end{array}\right]^{T}\left[\begin{array}{lll}
M_{r r} & M_{r u_{T}} & M_{r_{T}} \\
M_{u_{T} r} & M_{u_{T} u_{T}} & M_{u_{T} v_{T}} \\
M_{v_{T} r} & M_{v_{T} u_{T}} & M_{v_{T} v_{T}}
\end{array}\right]\left\{\begin{array}{l}
\dot{U}_{r} \\
\dot{u}_{T} \\
\dot{v}_{T}
\end{array}\right\}+1 / 2\left(m_{T}+m_{p}\right)\left(\dot{u}_{T}^{2}+\dot{v}_{T}^{2}+\dot{x}_{T}^{2}+2 \dot{u}_{T} \dot{x}_{T}\right) \\
& +1 / 2 m_{p}\left(\begin{array}{l}
\dot{u}_{T}^{2}+\dot{v}_{T}^{2}+\dot{x}_{T}^{2}+2 \dot{u}_{T} \dot{x}_{T} \\
+2\left(\ell_{P} \cos \theta \dot{\theta}+\sin \theta \dot{\delta}+\delta \cos \theta \dot{\theta}\right) \dot{x}_{T} \\
+2\left(\ell_{P} \cos \theta \dot{\theta}+\sin \theta \dot{\delta}+\delta \cos \theta \dot{\theta}\right) \dot{u}_{T} \\
+\ell_{P}^{2} \dot{\theta}^{2}+\dot{\delta}^{2}+\delta^{2} \dot{\theta}^{2}+2 \ell_{P} \delta \dot{\theta}^{2}
\end{array}\right)-\frac{1}{2}\left\{\begin{array}{l}
U_{r} \\
u_{T} \\
v_{T}
\end{array}\right]^{T}\left[\begin{array}{lll}
K_{r r} & K_{r u_{T}} & K_{r v_{T}} \\
K_{u_{T} r} & K_{u_{T} u_{T}} & K_{u_{T} v_{T}} \\
K_{v_{T} r} & K_{v_{T} u_{T}} & K_{v_{T} v_{T}}
\end{array}\right]\left\{\begin{array}{l}
U_{r} \\
u_{T} \\
v_{T}
\end{array}\right\} \\
& -\left(m_{T}+m_{p}\right) g H_{F}-\left(m_{T}+m_{p}\right) g v_{T}+m_{p} g\left(\ell_{P}+\delta\right) \cos \theta-1 / 2 k \delta^{2}
\end{aligned}
$$

Due to the carriage traverses along the top beam of portal framework, and assumed that the moving carriage carrying a planar payload pendulum modeled as moving lumped mass is always in contact with the top beam, the axial $\left(u_{T}\right)$ and vertical $\left(v_{T}\right)$ vibration of the portal framework are based on position $x_{T}$ and timet of carriage. The axial $(x)$ and vertical $(y)$ displacements of portal framework element at position $x$, can be obtained as below,

$$
\begin{aligned}
& u=N_{1} d_{s_{1}}+N_{4} d_{s 4} \\
& v=N_{2} d_{s_{2}}+N_{3} d_{s_{13}}+N_{5} d_{s_{5}}+N_{6} d_{s_{6}}
\end{aligned}
$$

where $d_{s i}=(i=1-6)$ are the displacements for the nodes of the portal frame element at which the carriage locates. Thus, the Eq. (9) can be rewritten as follows.

$$
\begin{aligned}
& u(x, t)=\left\{N_{k}\right\}_{u}\left\{d_{s_{k}}\right\}_{u} \\
& v(x, t)=\left\{N_{k}\right\}_{v}\left\{d_{s_{k}}\right\}_{v}
\end{aligned}
$$

Terms $\quad\left\{N_{k}\right\}_{u} \quad u=k=1,4 \quad$ and $\left\{N_{k}\right\}_{v} \quad v=k=2,3,5,6$ are shape functions of 2D beam element associated with translation degrees of freedom in three directions axial $(x)$ and vertical $(y)$, and terms $\left\{d_{s_{k}}\right\}_{u},\left\{d_{s_{k}}\right\}_{v}$ are displacements in two directions.
Derivatives of $u(x, t)$ with respect to time $\mathrm{t}$ and position $x$ are in Eq. (11a),

$$
\begin{gathered}
\frac{\partial u(x, t)}{\partial t}=\frac{\partial u(x, t)}{\partial x} \frac{\partial x}{\partial t}+\frac{\partial u(x, t)}{\partial t} \frac{\partial t}{\partial t} \\
=u^{\prime}(x, t) \dot{x}+\dot{u}(x, t) \\
\frac{\partial^{2} u(x, t)}{\partial t^{2}}=\frac{\partial u^{\prime}(x, t)}{\partial x} \frac{\partial x}{\partial t} \dot{x}+\frac{\partial u^{\prime}(x, t)}{\partial t} \frac{\partial t}{\partial t} \dot{x} \\
+u^{\prime}(x, t) \frac{\partial \dot{x}}{\partial t}+\frac{\partial \dot{u}(x, t)}{\partial x} \frac{\partial x}{\partial t}+\frac{\partial \dot{u}(x, t)}{\partial t} \frac{\partial t}{\partial t} \\
=u^{\prime \prime}(x, t) \dot{x}^{2}+2 \dot{u}^{\prime}(x, t) \dot{x} \\
+u^{\prime}(x, t) \ddot{x}+\ddot{u}(x, t) .
\end{gathered}
$$

Derivatives of $v(x, t)$ with respect to time $t$ and position $x$ are in Eq. (11b),

$$
\begin{gathered}
\frac{\partial v(x, t)}{\partial t}=\frac{\partial v(x, t)}{\partial x} \frac{\partial x}{\partial t}+\frac{\partial v(x, t)}{\partial t} \frac{\partial t}{\partial t} \\
=v^{\prime}(x, t) \dot{x}+\dot{v}(x, t) \\
\frac{\partial^{2} v(x, t)}{\partial t^{2}}=\frac{\partial v^{\prime}(x, t)}{\partial x} \frac{\partial x}{\partial t} \dot{x}+\frac{\partial v^{\prime}(x, t)}{\partial t} \frac{\partial t}{\partial t} \dot{x} \\
+v^{\prime}(x, t) \frac{\partial \dot{x}}{\partial t}+\frac{\partial \dot{v}(x, t)}{\partial x} \frac{\partial x}{\partial t}+\frac{\partial \dot{v}(x, t)}{\partial t} \frac{\partial t}{\partial t} \\
=v^{\prime \prime}(x, t) \dot{x}^{2}+2 \dot{v}^{\prime}(x, t) \dot{x} \\
+v^{\prime}(x, t) \ddot{x}+\ddot{v}(x, t) .
\end{gathered}
$$

Due to the carriage moves along a vibrating path, then Coriolis acceleration will occur as shown in Eq. (11). An example, Eq. (11a) is applied to the general element displacement in Eq. (10a) yields: 


$$
\begin{aligned}
& \frac{\partial v(x, t)}{\partial x}=\left\{N_{k} \cdot\right\}\left\{d_{s_{k}}\right\}_{v}, \frac{\partial^{2} v(x, t)}{\partial x^{2}}=\left\{N_{k} "\right\}\left\{d_{s_{k}}\right\}_{v} \\
& \frac{\partial v(x, t)}{\partial t}=\left\{N_{k}\right\}\left\{\dot{d}_{s_{k}}\right\}_{v}, \frac{\partial^{2} v(x, t)}{\partial t^{2}}=\left\{N_{k}\right\}\left\{\ddot{d}_{s_{k}}\right\}_{v} \\
& \left.\frac{\partial^{2} v(x, t)}{\partial x \partial t}=\left\{N_{k} \cdot\right\} \dot{d}_{s_{k}}\right\}_{v}
\end{aligned}
$$

This is also applicable for in Eq. (11b), where the terms $\left\{N_{k}{ }^{\prime}\right\}$ and $\left\{N_{k}{ }^{\prime}\right\}$ indicate the partial derivative of shape functions with respect to $X$. By substituting Eq. (12) into Eq. (11), an expression for the acceleration of the carriage, $(\ddot{u}(x, t), \ddot{v}(x, t))$, can be obtained,

$$
\begin{aligned}
& \ddot{u}(x, t)=(\dot{x}+\ddot{x} t)^{2}\left\{u_{s_{k}}\right\}_{u}\left\{N_{k}{ }^{\prime}\right\} \\
& +2(\dot{x}+\ddot{x} t)\left\{\dot{u}_{s_{k}}\right\}_{u}\left\{N_{k}{ }^{\prime}\right\} \\
& \left.\left.+\ddot{x}\left\{u_{s_{k}}\right\}_{u}\left\{N_{k}\right\}^{\prime}\right\}^{\prime} \ddot{u}_{s_{k}}\right\}_{u}\left\{N_{k}\right\} \\
& \ddot{v}(x, t)=(\dot{x}+\ddot{x} t)^{2}\left\{v_{s_{k}}\right\}_{v}\left\{N_{k}{ }^{\prime \prime}\right\} \\
& +2(\dot{x}+\ddot{x} t)\left\{\dot{v}_{s_{k}}\right\}_{v}\left\{N_{k}{ }^{\prime}\right\} \\
& +\ddot{x}\left\{v_{s_{k}}\right\}_{v}\left\{N_{k}\right\}^{\prime}+\left\{\ddot{v}_{s_{k}}\right\}_{v}\left\{N_{k}\right\} .
\end{aligned}
$$

Equation (13) represents the acceleration of the portal framework in terms of the shape functions, nodal displacements and the velocity and acceleration. Further, by deriving $L$ in Eq. (8) with respect to generalized coordinates and substituting into Eq. (1) together with Eq. (7), it yields equations, which derived and summarized in Eq. (14a)-(14d).

The system matrices in Eq. (14d) are time variant, with the entries being directly dependent upon the position of the point mass along the beam.

$$
\begin{aligned}
& \left(m_{T}+m_{p}\right)\left(\ddot{u}_{T}+2 \dot{u}_{T}^{\prime} \dot{x}_{T}+u_{T}{ }^{\prime} \dot{x}_{T}^{2}+u_{T}^{\prime} \ddot{x}_{T}+\ddot{x}_{T}\right)_{+} \\
& m_{P} \ell_{P}\left(\begin{array}{l}
\ddot{\theta} \cos \theta-\dot{\theta}^{2} \sin \theta+\ddot{\theta} \delta \cos \theta / \ell_{P} \\
-\delta \dot{\theta}^{2} \sin \theta / \ell_{P}+2 \dot{\delta} \dot{\theta} \cos \theta / \ell_{P}+\ddot{\delta} \sin \theta / \ell_{P}
\end{array}\right)=f_{x}
\end{aligned}
$$

$\left(\begin{array}{l}\left(\cos \theta / \ell_{P}+\delta \cos \theta / \ell_{P}{ }^{2}\right) \ddot{x}_{T}+\left(\cos \theta / \ell_{P}+\delta \cos \theta / \ell_{P}^{2}\right) \\ \left(\ddot{u}_{T}+2 \dot{u}_{T}{ }^{2} \dot{x}_{T}+u_{T}{ }^{2} \dot{x}_{T}^{2}+u_{T}{ }^{2} \ddot{x}_{T}\right)+\left(\sin \theta / \ell_{P}+\delta \sin \theta / \ell_{P}^{2}\right) \\ \left(\ddot{v}_{T}+2 \dot{v}_{T} \dot{x}_{T}+v_{T}{ }^{2} \dot{x}_{T}^{2}+v_{T}{ }^{2} \ddot{x}_{T}\right)+\left(1+\delta / \ell_{P}\right)^{2} \ddot{\theta} \\ +2 \dot{\delta} \dot{\theta} / \ell_{P}+g \sin \theta / \ell_{P}+g \delta \sin \theta / \ell_{P}{ }^{2}\end{array}\right)=0$

$$
\left(\begin{array}{l}
\sin \theta \dot{x}_{T} / \ell_{P}+\sin \theta / \ell_{P}\left(\ddot{u}_{T}+2 \dot{u}_{T}^{\prime} \dot{x}_{T}+u_{T}{ }^{\prime} \dot{x}_{T}^{2}+u_{T}^{\prime} \ddot{x}_{T}\right) \\
-\cos \theta / \ell_{P}\left(\ddot{v}_{T}+2 \dot{v}_{T} \dot{x}_{T}+v_{T}{ }^{\prime \prime} \dot{x}_{T}^{2}+v_{T}{ }^{2} \ddot{x}_{T}\right)-\dot{\theta}^{2}+\ddot{\delta} / \ell_{P} \\
-\delta \dot{\theta}^{2} / \ell_{P}-g \cos \theta / \ell_{P}+k \delta / m_{P} \ell_{P}
\end{array}\right)=0
$$

The coupling terms in equation (14a), $\left.m\left\{\left\{N_{k}\right\}^{T}\right\}\left\{N_{k}\right\} \quad, \quad 2 m V\left\{\left\{N_{k}\right\}^{T}\right\} N_{k}{ }^{\prime}\right\}$, $m V^{2}\left\{\left\{N_{k}\right\}^{T} \bigcup_{h} N_{k} "\right\}$ and $\left\{\left\{N_{k}\right\}^{T}\right\} m g$ are inertial, Coriolis, centrifugal force and gravitational load of moving carriage, respectively, which is time dependent, and move within the structural matrices as the moving lumped mass travels from one element to another. Notations $\left[M_{s t}\right],\left[C_{s t}\right],\left[K_{s t}\right]$ are the mass, damping and stiffness matrices of the portal framework, respectively. They are obtained by assembling all its all element mass and stiffness through the direct stiffness method, and imposing the prescribed boundary conditions.

Again, by assuming it is always in contact with the top beam of portal frame, there will be transmitted forces to the portal framework from the swinging payload pendulum through the hoist cable and contact force at contact point between the carriage and the top beam of portal frame. This is exciting forces for the portal frame in the $\mathrm{x}$ and $\mathrm{y}$ directions. The component and magnitude of these exciting forces are given by the right side of Eq. (14d). Under assumption that the crane framework is to be rigid or called rigid model, vibration in the Eq. (14) is vanished. 


$$
\begin{aligned}
& \left.\left.\left[M_{s t}\right]+\left[\begin{array}{ccc}
0 & 0 & 0 \\
0 & \left(m_{T}+m_{p}\right)\left\{N_{k}\right\}_{u}^{T}\left\{N_{k}\right\}_{u} & 0 \\
0 & 0 & \left(m_{T}+m_{p}\right)\left\{N_{k}\right\}_{v}^{T}\left\{N_{k}\right\}_{v}
\end{array}\right]\right)\right]\left\{\begin{array}{l}
\ddot{\Delta}_{r} \\
\ddot{u}_{T} \\
\ddot{v}_{T}
\end{array}\right\} \\
& +
\end{aligned}
$$

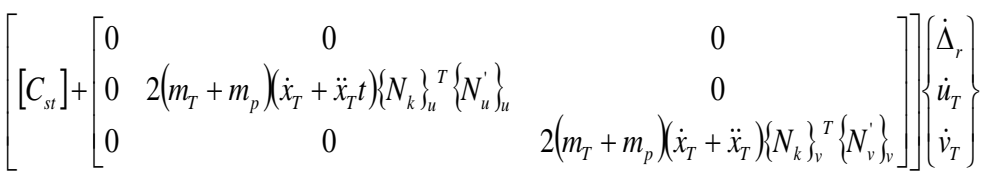

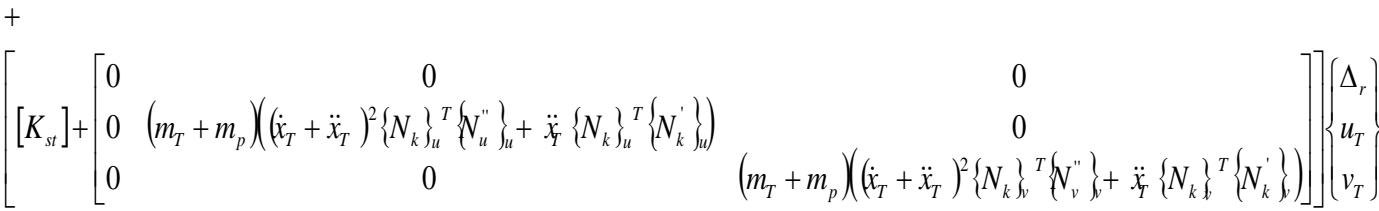

$$
\begin{aligned}
& =\left\{\begin{array}{c}
\left\{N_{k}\right\}_{u}^{T}\left(\begin{array}{c}
0 \\
\left.-\left(m_{T}+m_{p}\right) \ddot{x}_{T}+m_{p} \ell_{P}\left(\begin{array}{c}
-\ddot{\theta} \cos \theta+\dot{\theta}^{2} \sin \theta-\ddot{\theta} \delta \cos \theta / \ell_{P} \\
+\delta \dot{\theta}^{2} \sin \theta / \ell_{P}-2 \dot{\delta} \dot{\theta} \cos \theta / \ell_{P}-\ddot{\delta} \sin \theta / \ell_{P}
\end{array}\right)\right) \\
\left\{N_{k}\right\}_{v}^{T}\left(m_{p} \ell_{P}\left(\begin{array}{l}
-\ddot{\theta} \sin \theta-\dot{\theta}^{2} \cos \theta-\ddot{\theta} \delta \sin \theta / \ell_{P} \\
-\delta \dot{\theta}^{2} \cos \theta / \ell_{P}-2 \dot{\delta} \dot{\theta} \sin \theta / \ell_{P}+\ddot{\delta} \cos \theta / \ell_{P}
\end{array}\right)+\left(m_{T}+m_{p}\right) g\right.
\end{array}\right\}
\end{array}\right\}
\end{aligned}
$$

Equations of motion of the system can be reduced into classical 2D-pendulum system with moving pivot point and the results are the same with Newton's motion law as presented by Eq. (15a)-(15b),

$$
\begin{aligned}
& \left(m_{T}+m_{p}\right) \ddot{x}_{T}+m_{p}\left(\ddot{\theta} \cos \theta \cos \varphi-\dot{\theta}^{2} \sin \theta\right)=f_{x} \\
& \frac{\ddot{x}_{T}}{\ell} \cos \theta+\ddot{\theta}+\frac{g}{\ell} \sin \theta=0 .
\end{aligned}
$$

The damping matrix is assumed proportional to the combination of mass and stiffness matrices. Under this assumption, The Rayleigh damping theory is therefore used. The damping matrices can be written as,

$$
\left[C_{\text {st }}\right]=a\left[M_{\text {total }}\right]+b\left[K_{\text {total }}\right]
$$

The proportionality factors is calculated by using damping ratio $\zeta=\zeta_{1}=\zeta_{2}$ and natural frequency $\omega_{1}$ and $\omega_{2}$.

$$
\left\{\begin{array}{l}
a \\
b
\end{array}\right\}=\frac{2 \zeta}{\omega_{1}+\omega_{2}}\left\{\begin{array}{c}
\omega_{1} \omega_{2} \\
1
\end{array}\right\},
$$

\section{Remarks on the Equations of Motion}

Equation (14) calls for some remarks:

1. The term, $f_{x}$ is input force or driving force for the carriage motion while $\left(m_{T}+m_{P}\right)$ is mass total from carriage and payload. This term is an equivalent lumped mass which will be moving load in the portal framework. Position of the lumped mass is time-variant as reported in [8].

2. Equations (14a) - (14d) are equations of motion which represent the coupling between the dynamics of portal framework and payload pendulum. Equation (14a) presents dynamics of carriage motion with the driving force, while Eqs. (14b) - (14c) are dynamics of payload and dynamics of hoist cable, respectively.

3. Carriage acceleration $\left(\ddot{x}_{T}\right)$ appears as forcing term to the dynamics of payload pendulum as shown in Eqs. (14b) - (14c) if the carriage motion is prescribed.

4. There are contributions of axial and vertical acceleration of portal framework on the dynamics of payload pendulum. These contributions provide elastic moving support for the carriage carrying a payload pendulum.

5. There are effects of Coriolis and centrifugal forces in Eq. (14a) due to $\left(m_{T}+m_{P}\right)$ moves on deformed portal framework. 
6. Equations (14a) - (14d) have led to a system of equations which dynamics of payload pendulum are dependent on the dynamics of portal framework and conversely. The dependency is a bidirectional coupling, where elastic support of the payload pendulum motion offered by vibration of portal framework. This result is also found by [3] and [5].

\section{NUMERICAL APPROACH}

In the condition where the dynamics of payload pendulum and hoist cable are not introduced, the swing angle $\theta$ and hoist cable displacement $\delta$ on the right side of equation Eqs. (14a)-(14d) will be zero, the case would be moving load in portal framework, which is imposed by $\left(m_{t}+m_{P}\right)$ load. In order to solve those equations, the computational scheme under Newmark- $\beta$ and fourth-order Runge-Kutta method is proposed. The portal framework displacements are calculated by Newmark- $\beta$ method. The two parameters are selected as $\beta$ $=0.25$ and $\gamma=0.5$, which implies a constant average acceleration with unconditional numerical stability, while swing angle of payload pendulum are calculated by fourth-order RungeKutta method. For each integration step, Newmark- $\beta$ and Runge-Kutta methods are combined simultaneously to obtain the portal framework and the payload responses. The computational procedures with a time step of $\Delta t$ that performs the direct numerical integration can be summarized as follows:

1. Set initial condition for velocity and acceleration:

$$
\{q\}_{0}=\{q(t=0)\},\{\dot{q}\}_{0}=\{\dot{q}(t=0)\}
$$

2. The initial external force vector $\{F\}_{0}=\{F(t=0)\} \quad$ is calculated using right side of Eq. (8) by using initial conditions $\quad(\theta, \dot{\theta}, \ddot{\theta}, \varphi, \dot{\varphi}, \ddot{\varphi} \quad$ and $\delta, \dot{\delta}, \ddot{\delta}$ ) of payload.

3 . The initial acceleration vector is calculated as:

$$
\{\ddot{q}\}_{0}=\left[M_{\text {total }}\right]^{-1}\left\{\{F\}_{0}-\left[C_{\text {st }}\right]\{\dot{q}\}_{0}-\left[K_{\text {st }}\right]\{q\}_{0}\right\}
$$

4. Evaluation of constants from $a_{0}$ to $a_{7}$.The parameters $a_{i}$ are show in Table 1 .
Table 1.

Newmark's parameters.

$$
\begin{aligned}
& a_{0}=\frac{1}{\beta \Delta t^{2}} \quad a_{1}=\frac{\gamma}{\beta \Delta t} \quad a_{2}=\frac{1}{\beta \Delta t} \\
& a_{3}=\frac{1}{2 \beta}-1 \quad a_{4}=\frac{\gamma}{\beta}-1 \\
& a_{6}=\Delta t(1-\gamma) \quad a_{7}=\gamma \Delta t \\
& a_{5}=\frac{\Delta t}{2}\left(\frac{\gamma}{\beta}-2\right)
\end{aligned}
$$

5. The effective stiffness matrix $\{\bar{K}\}$ is calculated as follows.

$$
\{\bar{K}\}=\left[K_{\text {st }}\right]+a_{0}\left[M_{\text {total }}\right]+a_{1}\left[C_{s t}\right]
$$

6. For each time step:

Equations (6a)-(6c) are solved to obtain $\theta, \dot{\theta}, \ddot{\theta}, \varphi, \dot{\varphi}, \ddot{\varphi}$ and $\delta, \dot{\delta}, \ddot{\delta} \quad$ using fourth-order Runge-Kutta and external force vector $\{F\}_{t+\Delta t}$ is then updated. The force vector $\{F\}_{t+\Delta t}$ denotes the external loads of the system at time $t+\Delta t$.

Equation of motion of the system is represented as below.

$[\bar{K}]\{q\}_{t+\Delta t}=\{\bar{F}\}_{t+\Delta t}$

The effective load vector $\{\bar{F}\}$ is below.

$$
\{\bar{F}\}_{t+\Delta t}=\{F\}_{t+\Delta t}+\left[M_{\text {total }}\right]\left(a_{0}\{q\}_{t}+a_{2}\{\dot{q}\}_{t}+a_{3}\{\ddot{q}\}_{t}\right)
$$

The displacement, velocity and acceleration responses are computed with satisfying the following relationships.

$$
\begin{aligned}
& \{q\}_{t+\Delta t}=[\bar{K}]^{-1}\{\bar{F}\}_{t+\Delta t} \\
& \{\ddot{q}\}_{t+\Delta t}=a_{0}\left(\{q\}_{t+\Delta t}-\{q\}_{t}\right)-a_{2}\{\dot{q}\}_{t}-a_{3}\{\ddot{q}\}_{t} \\
& \{\dot{q}\}_{t+\Delta t}=\{\dot{q}\}_{t}+a_{6}\{\ddot{q}\}_{t}+a_{7}\{\ddot{q}\}_{t+\Delta t}
\end{aligned}
$$

\section{NUMERICAL SimUlations}

The cross-section of portal framework is uniform, isotropic and homogeneous material properties. The gravitational acceleration is $g=$ $9.81 \mathrm{~m} / \mathrm{s}^{2}$ and time interval is $\Delta t=0.005 \mathrm{~s}$. Portal 
framework is discretized into 20 beam elements: 10 elements for the top beam, the left side-beam have 2 members with 10 identical elements and so does the right-side beam. The issue of total number of elements and nodes will not be treated as a parameter that will be varied in the simulations.

\section{A. Moving Load Case}

In this subsection, as a test for the mathematical model in Eq. (14), simulations are performed under moving load with constant velocity by setting up the swing angle and hoist cable displacement $\theta=\delta=0$. It is noted that the simulation is conducted to primarily attempt to verify the developed computer program in tackling moving load case in portal framework. The dimensions for portal are shown in Table 2.

The portal framework is subjected to a load moving from the left end to the right end of the top beam with constant velocity $V=0.75 \mathrm{~m} / \mathrm{s}, \mathrm{m}$ $=60 \mathrm{~kg}$. Dynamic responses in the axial $(X)$ and vertical $(Y)$ displacements of central point $C_{p}$ of the top beam induced by moving force, moving mass are shown in Fig. 2.

Agreement in fluctuating features of the associated curve among moving mass, moving

Table 2.

Portal framework dimensions.

\begin{tabular}{|c|c|c|}
\hline \multirow[b]{2}{*}{ Properties } & \multicolumn{2}{|c|}{ Values } \\
\hline & $\begin{array}{c}\text { Top Beam } \\
\text { Support }\end{array}$ & Top Beam \\
\hline Young's Modulus, E & \multicolumn{2}{|c|}{$2.10 \mathrm{e} 11 \mathrm{~kg} / \mathrm{m}^{2}$} \\
\hline Density, $\rho$ & \multicolumn{2}{|c|}{$7860 \mathrm{~kg} / \mathrm{m}^{3}$} \\
\hline Cross-section Area, $A$ & $3.45 \mathrm{e}-2 \mathrm{~m}^{2}$ & $1.51 \mathrm{e}-2 \mathrm{~m}^{2}$ \\
\hline Span of Framework, $L_{B}$ & \multicolumn{2}{|c|}{$12 \mathrm{~m}$} \\
\hline Framework Height, $H_{F}$ & \multicolumn{2}{|c|}{$10.6 \mathrm{~m}$} \\
\hline
\end{tabular}

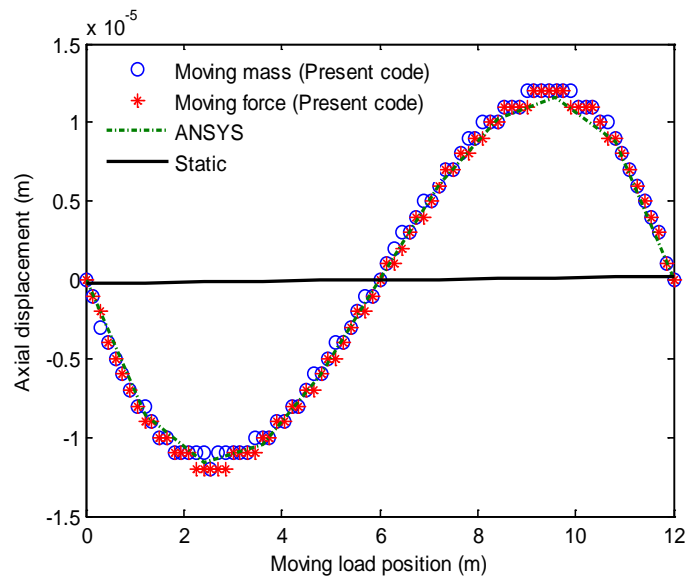

(a) force obtained from present code under Matlab ${ }^{\circledR}$ and ANSYS ${ }^{\circledR}$ are found. In those figures, it is also seen that besides the vertical responses, moving loads have significant effect in axial response compared to their corresponding static responses.

\section{B. Test for the Mathematical Model}

After verification of the developed computer program, the equations of motion of the system in Eq. (14) are tested under some types of driving forces. The parameters of the overall system are still exactly the same as those in the Table 2 and Table 3.

It is noted that that there is no damping either in dynamics of crane framework or payload, unless particularly stated. This is expected to avoid the effect of structural damping in dynamics of payload and make it a direct comparison with the pendulum model.

The carriage is moved by bang-bang input force as driving force. The amplitude and time switch of driving force are varied to generate different velocity level of carriage as depicted in Fig. 3. It is noted that that other forms of driving

Table 3.

Payload pendulum parameters.

\begin{tabular}{ll}
\hline Parameters & Values \\
\hline Carriage mass, $m_{T}$ & $50 \mathrm{~kg}$ \\
\hline Payload mass, $m_{p}$ & $120 \mathrm{~kg}$ \\
\hline Cable length, $\ell_{P}$ & $1 \mathrm{~m}$ \\
\hline Stiffness cable, $k$ & $2.5 \mathrm{e} 5 \mathrm{~N} / \mathrm{m}$ \\
\hline Initial angle, $\theta_{o}, \dot{\theta}_{0}, \ddot{\theta}_{0}$ & $5^{\circ}, 0,0$ \\
\hline Initial angle, $\varphi_{o}, \dot{\varphi}_{o}, \ddot{\varphi}_{o}$ & $5^{\circ}, 0,0$ \\
\hline Initial cable displacement $\delta_{o}, \dot{\delta}_{o}, \ddot{\delta}_{o}$ & Static, 0,0 \\
\hline
\end{tabular}

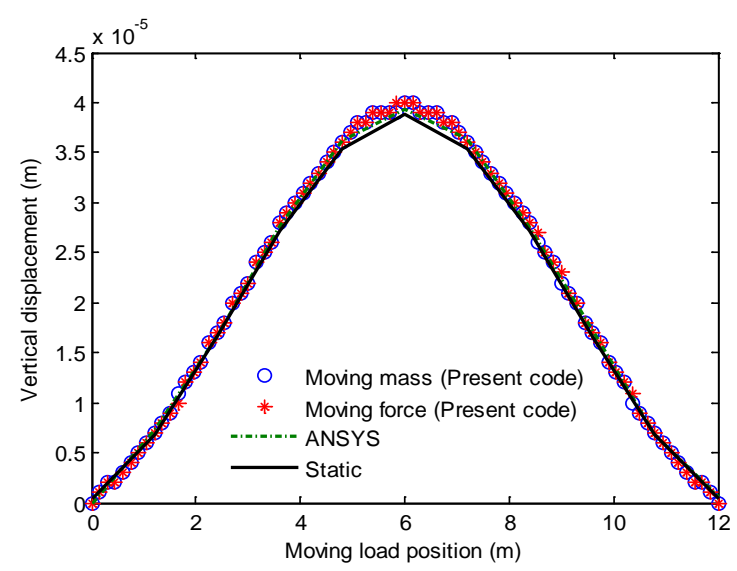

(b)

Figure 2. Displacements of the central point $C_{p}$ of the top beam, (a) axial, (b) vertical. 
(a)

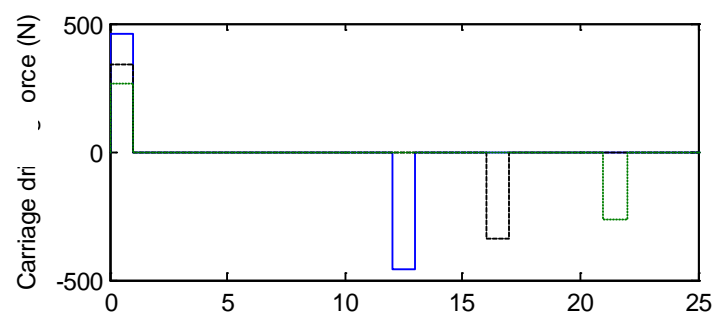

(b)

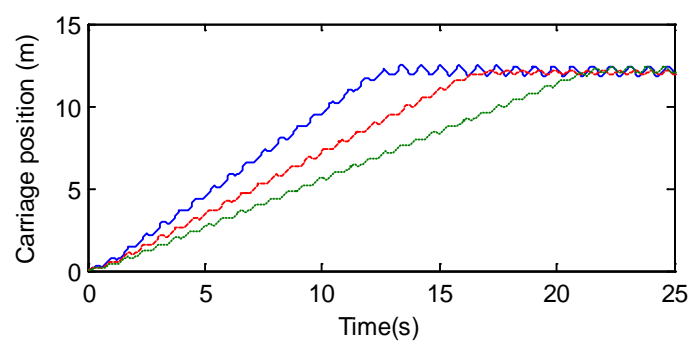

Figure 3. Time histories of carriage driving force and position with (-) $1^{\text {st }}$ driving force, $(--) 2^{\text {nd }}$ driving force, (- - -) $3^{\text {rd }}$ driving force. (a) carriage driving force, (b) carriage position.

force could have been chosen, but here an arbitrary form is chosen to primarily attempt to model the real driving force situation for the actual crane system.

As a benchmark, rigid model of the system is used. Rigid model means that the members of portal framework and hoist cable are rigid and equivalent with classical pendulum with moving pivot point. By observing Fig. 4, it can be seen that flexible model have longer periods or lower frequencies than the rigid model. The figure depicts that $\theta_{\text {flexible }}$ and $\theta_{\text {rigid }}$ have a phase shift over the entire cycles of prescribed time duration. The phase shift must be caused by the contribution of flexibility of the portal framework and hoist cable by providing acceleration in two directions to the pivot point of payload pendulum as shown in equations (14a) - (14d). It also may be observed that magnitude of swing angle of payload pendulum of flexible model is smaller than the rigid one, which is similar with work [1] and [10].

The rigid and flexible model deviation $\Delta \theta$ is shown in Fig. 5, where $\Delta \theta=\theta_{\text {flexible }}-\theta_{\text {rigid }}$. The deviation between the rigid assumption and the flexible model results is clearly observed. The faster the carriage moves, the bigger $\Delta \theta$ is. Further, Fig. 5 shows a beating phenomenon in the time histories of $\Delta \theta$. The beating phenomenon appears in $\Delta \theta$ plot because of the superimposed plot of the rigid and flexible response. The deviation between rigid and (a)

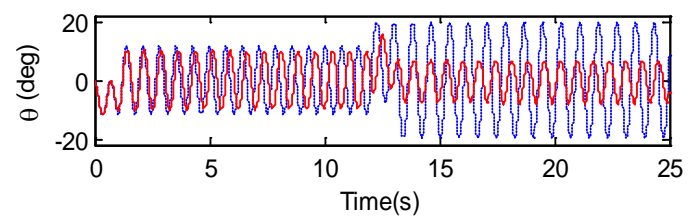

(b)

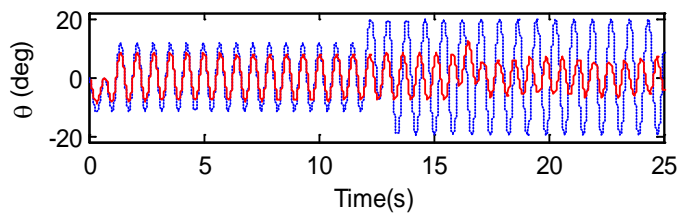

(c)

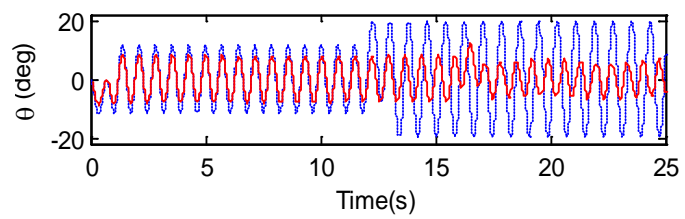

Figure 4. Time history of $\theta$ with (-) flexible model, (- - -) rigid model. (a) $1^{\text {st }}$ driving force, (b) $2^{\text {nd }}$ driving force, (c) $3^{\text {rd }}$ driving force.

(a)

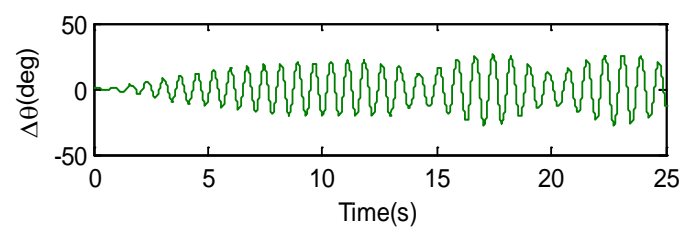

(b)

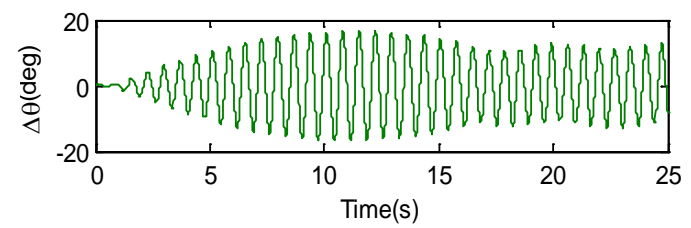

(c)

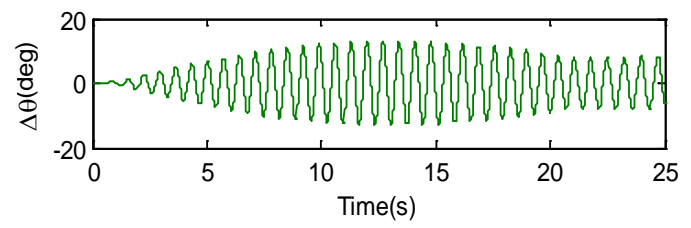

Figure 5. Time history of $\Delta \theta$ with (-) flexible model, (- - -) rigid model. (a) $1^{\text {st }}$ driving force, (b) $2^{\text {nd }}$ driving force, (c) $3^{\text {rd }}$ driving force.

flexible model is also pronounced by spectral analysis in Table 4 and their statistical properties in Table 5. Table 4 confirms that swing angles frequency of flexible model is lower than that of the rigid model. This is expected since the rigid model is stiffer than the flexible model. That is why the stiffer model vibrates at a higher frequency. It is noted that the linear natural frequency for swing angles of rigid model are consistent with the frequency obtained from Eqs. (15a)-(15b). 
Table 4.

Spectral analysis.

\begin{tabular}{lccc}
\hline Model & \multicolumn{3}{c}{ Dominant frequency of $\boldsymbol{\theta}(\mathbf{H z})$} \\
\cline { 2 - 4 } & $\begin{array}{c}\mathbf{1}^{\text {st }} \text { driving } \\
\text { force }\end{array}$ & $\begin{array}{c}\mathbf{2}^{\text {nd }} \text { driving } \\
\text { force }\end{array}$ & $\begin{array}{c}\mathbf{3}^{\text {rd }} \text { driving } \\
\text { force }\end{array}$ \\
\hline Rigid & 5.38 & 4.7 & 4.2 \\
\hline Flexible & 2.92 & 2.7 & 2.2 \\
\hline
\end{tabular}

Table 5.

Statistics of $\theta$.

\begin{tabular}{lccc}
\hline Statistics & $\begin{array}{c}\mathbf{1}^{\text {st }} \text { driving } \\
\text { force }\end{array}$ & $\begin{array}{c}\mathbf{2}^{\text {nd }} \text { driving } \\
\text { force }\end{array}$ & $\begin{array}{c}\mathbf{3}^{\text {rd }} \text { driving } \\
\text { force }\end{array}$ \\
\hline \multirow{2}{*}{ Mean } & $*-1.1 \cdot 10^{-3}$ & $*-3.19 \cdot 10^{-4}$ & $*-4.56 \cdot 10^{-4}$ \\
\cline { 2 - 4 } & $a-1.3 \cdot 10^{-3}$ & $a 4.5 \cdot 10^{-4}$ & $\circ 6.37 \cdot 10^{-4}$ \\
\hline \multirow{2}{*}{ Skewness } & $* 4.4 \cdot 10^{-2}$ & $* 2.82 \cdot 10^{-2}$ & $* 1.06 \cdot 10^{-1}$ \\
\cline { 2 - 4 } & $a 3.66 \cdot 10^{-2}$ & $a 4.4 \cdot 10^{-2}$ & $a 6.45 \cdot 10^{-2}$ \\
\hline \multirow{2}{*}{ Kurtosis } & $* 1.816$ & $* 1.644$ & $* 1.273$ \\
\cline { 2 - 4 } & $a 1.751$ & $a 1.657$ & $a 1.357$ \\
\hline
\end{tabular}

* rigid model, a flexible model.

\section{Conclusion}

By applying Lagrange's approach in conjunction with finite element method, equations of motion of a moving planar payload pendulum on flexible portal framework have been derived. The equations show that the payload behaves as a pendulum system with moving flexible support which undergoes accelerations in two directions. There is nonlinear coupling between payload pendulum and portal framework. If the flexibility of cable and portal frame are not accounted, then the equations of motion are greatly simplified as classical pendulum with moving pivot point the results are the same with Newton's motion law.

The effects of elasticity in hoist cable and portal framework on the dynamics of a moving planar payload pendulum have been investigated. It has been shown that the vibration amplitudes and frequencies are significantly affected. This paper also recommends that flexibility either structural members or hoist cable must be included in the mathematical model for vibration control design.

\section{REFERENCES}

[1] R. Hui-li, et al. "Dynamic response analysis of a moored ship-crane with a flexible boom," Journal of Zhejiang University Science A, Volume 9, Issue 1, pp. 26-31, 2008.
[2] G. Sun and J. Liu, "Dynamic responses of hydraulic crane during luffing motion," Mechanism and Machine Theory, Volume 41, Issue 11, pp. 1273-1288, November 2006.

[3] D.C.D. Oguamanam and J.S. Hansen, "Dynamics of a three-dimensional overhead crane system," Journal of Sound and Vibration, Volume 242, Issue 3, pp. 411-442, May 2001.

[4] Jerman, B., Podrzaj, P., and Kramar, J., “An investigation of slewing-crane dynamics during slewing motion-development and verification of a mathematical model," International Journal of Mechanical Sciences, Volume 46, Issue 5, pp. 729-750, 2004.

[5] W. Yang, et al., "Modeling of system dynamics of a slewing flexible beam with moving payload pendulum," Mechanics Research Communications, Volume 34, Issue 3, pp. 260-266, 2007.

[6] J.J. Wu, "Transverse and longitudinal vibrations of a frame structure due to a moving trolley and the hoisted object using moving finite element," International Journal of Mechanical Sciences, Volume 50, Issue 4, pp. 613-625, April 2008.

[7] F. Ju, Y.S. Choo, and F.S. Cui, "Dynamic response of a tower crane induced by the pendulum motion of the payload," International Journal of Solids and Structures, Volume 43, Issue 2, pp. 376-389, January 2006.

[8] J.J. Wu, "Dynamic responses of a threedimensional framework due to a moving carriage hoisting a swinging object," International Journal for Numerical Methods in Engineering, Volume 59, Issue 13, pp. 1679-1702, April 2004.

[9] Ziyad N. Masoud, "Effect of hoisting cable elasticity on anti-sway controllers of Quayside container cranes," Nonlinear Dynamic, Volume 58, Numbers 1-2, pp. 129-140, 2009.

[10] E. Yazid, et al. "Vibration analysis of flexible gantry crane system subjected swinging motion of payload," Journal of Applied Sciences, Volume 11, Issue 10, pp. 1707-1715, 2011. 